\title{
Panel Size, Clinician Time in Clinic, and Access to Appointments
}

\author{
David Margolius, $M D^{1}$ \\ Douglas Gunzler, $P b D^{2}$ \\ Michael Hopkins, MBA ${ }^{3}$ \\ Katbryn Teng, MD, MBA ${ }^{1}$ \\ 'Department of Medicine, MetroHealth \\ System, Cleveland, Ohio \\ ${ }^{2}$ Center for Health Care Research and \\ Policy, Case Western Reserve University, \\ Cleveland, Ohio \\ ${ }^{3}$ MetroHealth System, Cleveland, Ohio
}

\begin{abstract}
Large panel sizes are often held responsible for worse access to appointments in primary care. We evaluated the relationship between appointment backlog, panel size, and primary care clinician time in clinic, using Spearman correlation and multiple regression in a retrospective analysis. We found no independent association between panel size and days until third next available appointment, but larger panel size adjusted for clinician time in clinic was associated with worse access. Less clinician time in clinic was independently associated with longer backlogs for appointments. Our findings suggest that patients of part-time clinicians may be less likely to obtain timely appointments than patients of fulltime clinicians, regardless of panel size.
\end{abstract}

Ann Fam Med 2018;16:546-548. https://doi.org/10.1370/afm.2313.

\section{INTRODUCTION}

$\mathrm{T}$ imely access to appointments is foundational to a primary care clinician's ability to improve the health of his or her patients. ${ }^{1}$

Despite being a key to reducing hospital readmissions and unnecessary emergency department visits, available appointments for established patients are in limited supply. ${ }^{2,3} \mathrm{With}$ an increasing primary care workforce shortage, available follow-up appointments could become more scarce.

Limited research exists evaluating the factors associated with worse availability of appointments for established primary care patients. Previous studies have investigated the relationship between access and panel size and between access and part-time status of clinicians, but no study has evaluated the independent relationship of all 3 variables., ${ }^{4,5}$ Our objective was to investigate whether waits for appointments were associated with panel sizes and number of clinical half-days working in primary care. Our a priori hypothesis was that larger panel sizes, after adjustment for the number of worked weekly half-day sessions, would be associated with worse access to primary care.

\section{METHODS}

We performed a retrospective analysis to evaluate the association between our outcome, an access metric, and the number of patients attributed to a primary care clinician (panel size) and a clinician's full-time equivalent value (FTE). We first performed bivariate analyses by using Spearman correlation. Confidence intervals for Spearman correlation coefficients were obtained by bootstrapping methods. We also performed multiple regression analysis, additionally controlling for number of clinicians per site. We standardized all variables in the regression model to recast model regression coefficients on a scale similar to a correlation coefficient for ease of interpretation regarding effect sizes. The study was reviewed by the MetroHealth Institutional Review Board and determined to be exempt.

MetroHealth System is a tertiary academic health care system in northeast Ohio that cares for a diverse payer mix. Clinicians in our study 
were attending physicians or advanced practice providers with independent primary care patient panels. Clinicians did not team up to share panels.

We excluded 22 clinicians with incomplete access data: 15 worked at more than 1 site, and 7 began work during the 12-week data collection period. After exclusions, we analyzed 114 clinicians.

We calculated panel size as the sum of the number of unique patients a clinician has seen in the last 2 years who have that clinician's name listed in their chart's primary care clinician field plus unique patients seen in the last 2 years who are not otherwise attributed to a different clinician.

The clinician's FTE was determined by the number of weekly half-day sessions that the clinician works in clinic seeing his or her own primary care patients rather than supervising residents or working in a specialty clinic. An FTE of 0.5 corresponds to working 5 half-days in clinic. ${ }^{6}$

Access to primary care was measured as the number of days until third next available appointment (TNAA), a more reliable metric than first or second next available appointment because of distortions from last-minute cancellations. ${ }^{1}$ We calculated TNAA for each clinician weekly and averaged values over a 12-week period to account for fluctuations from vacations or other episodes that would have reduced available appointments.

\section{RESULTS}

Clinicians were predominantly physicians ( 87 vs 27 advanced practice providers), included 5 specialties (44 family medicine, 42 internal medicine, 13 medicine-pediatrics, 13 pediatrics, and 2 geriatrics), and practiced at 20 locations. Mean panel size was 1,146 patients (SD 618), mean FTE was 0.65 (SD 0.27 ), and mean TNAA was 25 days (SD 20).

Third next available appointment was negatively correlated with FTE (Spearman correlation coefficient $=-0.38[95 \% \mathrm{CI},-0.53$ to -0.23$]$ ), and the correlation between TNAA and panel size was close to zero $(-0.04$ [95\% CI, -0.21 to 0.14$])$. Our multiple regression analysis showed that in adjusted analyses TNAA was still negatively correlated with FTE and positively correlated with panel size (Table 1). Third next available appointment was not significantly associated with number of clinicians per site in our multiple regression model (Table 1).

\section{DISCUSSION}

Lower FTE, independent of panel size and number of clinicians per site, was associated with worse access to primary care appointments. Panel size, without adjustment for FTE and number of clinicians per site, had almost no correlation with access.

This is the largest study to evaluate the relationship between access, panel size, and FTE and the first we know of to study their independent relationships. A smaller study of family physicians at 3 sites found that worse access was correlated with larger panel sizes divided by FTE. ${ }^{4}$ A separate study of internal medicine and family medicine physicians found a negative association between days until TNAA and FTE, but the authors did not include analysis of the variables' relationship to panel sizes. ${ }^{5}$ Our study builds on findings that less clinician time in clinic is an independent contributor to worse access in primary care.

One study limitation is that clinicians in our study all practiced in a single health care system, however, the group included multiple specialties, disciplines, and diverse locations, including 2 of 20 sites that were hospital-based teaching practices. Another limitation was our inability to analyze patient characteristics that could determine access by affecting visit frequency. A third limitation was that our metrics were static; a future study could investigate how changes in FTE might affect access over time. A fourth limitation was that our conversion of 1.0 FTE to 10 half-days seeing patients in clinic is not universal. Some full-time clinicians might have 1 or 2 half-days of protected time to address their in-boxes and paperwork.

Despite the study limitations, our findings indicate that part-time clinicians may be less able to offer timely appointments to their patients than their fulltime counterparts. This is an important finding given the increasing proportion of clinicians who work parttime. ${ }^{5}$ One solution is that clinicians could team up with each other to comanage their panel and deliver more timely access to appointments for their patients. ${ }^{7,8}$ A second solution is that clinicians could team up with nonclinician team members to reduce the need for

\begin{tabular}{|c|c|c|c|}
\hline & Partial $r$ & SE & $P$ Value \\
\hline FTE & -0.51 & 0.11 & $<.001$ \\
\hline Clinicians/site & 0.12 & 0.09 & .220 \\
\hline Panel size & 0.22 & 0.10 & .032 \\
\hline
\end{tabular}

FTE = clinician full-time equivalent value; $r=$ correlation coefficient; SE = standard error.

Note: We report the estimate of the partial $r, S E$, and $P$ value via an $F$ test for each independent variable, with the access outcome (days until third next available appointment) controlling for the other 2 independent variables in the standardized multiple regression model. Multiple $R^{2}=0.22$; adjusted $R^{2}=0.20$. 
traditional face-to-face clinician visits. ${ }^{9}$ A third solution of reducing panel sizes may not be as feasible, or as important, as a clinician being present in clinic.

To read or post commentaries in response to this article, see it online at http://www.AnnFamMed.org/content/16/6/546.

Key words: access to care; primary care; workforce

Submitted April 25, 2018; submitted, revised, August 19, 2018; accepted September 4, 2018.

\section{References}

1. Murray M, Berwick DM. Advanced access: reducing waiting and delays in primary care. JAMA. 2003;289(8):1035-1040.

2. Chou SC, Deng Y, Smart J, et al. Insurance status and access to urgent primary care follow-up after an emergency department visit in 2016. Ann Emerg Med. 2018;71(4):487-496 e1.
3. Misky GJ, Wald HL, Coleman EA. Post-hospitalization transitions: examining the effects of timing of primary care provider follow-up. J Hosp Med. 2010;5(7):392-397.

4. Angstman KB, Horn JL, Bernard ME, et al. Family medicine panel size with care teams: impact on quality. J Am Board Fam Med. 2016; 29(4):444-451.

5. Panattoni L, Stone A, Chung S, Tai-Seale M. Patients report better satisfaction with part-time primary care physicians, despite less continuity of care and access. J Gen Intern Med. 2015;30(3):327-333.

6. Green LV, Savin S, Lu Y. Primary care physician shortages could be eliminated through use of teams, nonphysicians, and electronic communication. Health Aff (Millwood). 2013;32(1):11-19.

7. Norful AA, de Jacq K, Carlino R, Poghosyan L. Nurse practitionerphysician comanagement: a theoretical model to alleviate primary care strain. Ann Fam Med. 2018;16(3):250-256.

8. Bodenheimer T, Haq C, Lehmann W. Continuity and access in the era of part-time practice. Ann Fam Med. 2018;16(4):359-360.

9. Ghorob A, Bodenheimer T. Sharing the care to improve access to primary care. N Engl J Med. 2012;366(21):1955-1957.

\section{CHANGE-OF-ADDRESS FORM \\ FAMILY MEDICINE}

Please complete this form and mail to the following address or fax to Annals Circulation at 913-906-6080:

Annals of Family Medicine, Circulation Department, 11400 Tomahawk Creek Pkwy, Leawood, KS 66211-2680

Check if member of sponsoring organization:

$$
\begin{aligned}
& \square \text { AAFP } \square \text { ABFM } \square \text { STFM } \square \text { ADFM } \\
& \square \text { AFMRD } \square \text { NAPCRG } \square \text { CFPC }
\end{aligned}
$$

ID number from label on your journal cover

OLD Information (Please print.)

\begin{tabular}{ll}
\hline Name \\
\hline Company (if applicable) \\
\hline Address (Street plus Apt or Ste) \\
\hline City & Postal Code (9-digit ZIP for US) \\
\hline Country & Fax \\
\hline Telephone & \\
\hline E-Mail &
\end{tabular}

NEW Information (Please print.)

\begin{tabular}{lc}
\hline Name \\
\hline Company (if applicable) \\
\hline Address (Street plus Apt or Ste) \\
\hline City & Postal Code (9-digit ZIP for US) \\
\hline Country & Fax \\
\hline Telephone & \\
\hline E-Mail &
\end{tabular}

